\title{
6 Harmonizing the Measurement of On-Farm Impacts
}

\author{
Patrick Holden and Adele Jones
}

\section{If the Food System is an Organism, its Farms are the Cells}

Imagine the world's food systems as a giant organism, with its component parts, including the farmers, growers, abattoirs, packhouses, processors, distributors, and retailers all contributing to its overall health. In that immensely complex yet interconnected system, the farms are the cells. Building on this metaphorif the patient Earth is sick and the farms represent the cells fueling the planet's lungs and digestive system-it will clearly be impossible to restore the food system to full vitality without first ensuring that the cells (the farms) are healthy.

Without question, enabling such a transition to farm cellular health is of critical importance. As the leading environmentalist, Dr. Vandana Shiva, observed in a talk she gave in London in 2019, as the vast majority of planet Earth is now covered with farms, the only way to avert irreversible climate change and a likely associated population collapse is to enable a global transition to more healthy, sustainable, and resilient farming methods. Indeed, many countries are including food and land use in their nationally determined contributions (NDCs) as they strive to achieve their long-term climate goals under the United Nations Framework Convention on Climate Change. However these NDCs often reflect purely technical fixes, neglecting the need for holistic and systemic approaches (Leippert et al., 2020) reflecting challenges in mobilizing the agriculture sector and ensuring that farms actually deliver on the changes required.

Thankfully, there is now a growing consensus that in relation to the range of increasingly existential threats to human civilization (including climate change, biodiversity loss, depletion of natural capital, pollution, and growing food insecurity), farming has not only been one of the most significant contributors to the damage, but also potentially holds the key to reversing it.

\section{Barriers to Change}

This leads to a key question: if such a consensus now exists, why is the transition not already underway? There are a number of reasons, the primary one being economics. At present, owing to the failure to place a value on the impacts associated with food and farming systems, those that degrade natural, 
social, and human capital are more profitable than their sustainable equivalents. As a result, the vast majority of the farming community are currently contributing to the problem rather than representing part of the solution.

Another barrier is the lack of a harmonized framework for measuring and valuing on-farm sustainability. The current plethora of overlapping sustainability assessments and certification schemes is time-consuming, costly, and bureaucratic for farmers. It is also frustrating for government agencies, nongovernmental organizations (NGO) and food companies, as well as confusing for consumers, who have no unified means of linking their purchasing power to support sustainable and healthy food production.

As a direct consequence of both of these problems, farmers and food companies have become locked into a cycle of dependence on commodity products, the production of which is damaging on multiple levels. At the same time, consumers, unaware that for every $£ 1$ they spend on food they are paying an additional $£ 1$ in 'hidden' costs (including through their taxes to clean up polluted waterways for example, or environmental degradation at the cost of generations to come), are forced to continue buying the apparently 'cheap food' which results from the most intensive and harmful production systems (Fitzpatrick and Young, 2017).

Given the severity of the situation we now find ourselves in with climate change and diet-related ill health to name but two issues, it begs the question, how can these key barriers to change be overcome? We believe the answer lies in combination of three key things:

- The emergence of an internationally harmonized framework for measuring and valuing on-farm sustainability.

- The application of True Cost Accounting, including through the introduction of the polluter pays principle and redirection of subsidies to support farming systems which deliver "public good" outcomes.

- An honest, transparent and thriving market for sustainably produced food.

Taken together, these mechanisms could enable the global adoption of farming practices that mitigate against climate change, reduce, and eventually eliminate the pollution of air and water, rebuild soil health, and reinstate biodiversity.

Based on our experience and the work of others, we will begin by addressing the first of the aforementioned barriers and thus a potential solution-the need for a common approach for measuring and valuing on-farm sustainability.

\section{An International Framework for Measuring and Valuing On-Farm Sustainability}

In order for the application of True Cost Accounting (TCA) at farm level to be successful, we must first agree on a common language, framework and metrics for measuring the impact of different farming practices. Then, and only then, 
can we begin to apply the discipline of TCA to monetize these impacts and thus correct the economic distortions described above.

Although this sequence of events might seem obvious now, it has taken us some time to realize the significance of getting this right. As this book has detailed, there are now a number of high-level frameworks for measuring and valuing food system-related natural and social capital impacts, most notably the TEEBAgriFood Evaluation Framework (The Economics of Ecosystem and Biodiversity, 2018). However, as yet, there is little information about how these can be utilized practically at the cellular farm level.

The Sustainable Food Trust (SFT) has had a long history of involvement in the development of TCA (see Box 6.1), but as we became increasingly aware of the need to work through this process, we resolved to focus our attention on catalyzing the emergence of an internationally harmonized framework for measuring on-farm sustainability.

At present, there is a diverse range of overlapping assessment tools and certification/labelling schemes for monitoring and communicating how well a farm is performing. This makes it impossible for consumers, farmers, food businesses, and policymakers to gain an accurate understanding of the comparative impact of products resulting from different methods of production, as well as having a polarizing effect on farming communities due to the "you're either certified or you're not" approach (see reference to organic standards in Box 6.1).

To address this problem and undertake this work, we began by establishing a British farmers and land managers working group to review the current diversity of different frameworks and tools. The composition of the group included a wide range of farming scales, practices, and enterprise types. Unsurprisingly, this included organic farming members, big and small, as well as conventional producers and large estates that had been at the forefront of producing high yields using technically efficient and intensive methods.

Our motives for undertaking this project were simple: as farmers, we were all subjected to multiple annual audits including organic inspections, government assessments, and other certification schemes to enable us to gain public funding and market access. However, none of these assessments ever gave us any indication about whether our farming enterprises were more or less sustainable than the year before! Realizing this, we decided to take things into our own hands and worked together to pull the best and most common elements of all the existing sustainability assessment tools and certification schemes, to eventually arrive at a draft framework of categories, indicators, and metrics that we believed had the potential to be used on any farm, whatever scale and intensity, anywhere in the world (of course while recognizing that there will need to be an element of "bespokeness" for different geographies, climates, and cultures).

In 2017 the group commissioned a thorough gap analysis of the most widely used sustainability assessment tools (Smith et al., 2017) and identified areas of overlap. This exercise further reinforced the case for harmonization, as it revealed to us that there was more than a $60 \%$ overlap of data requirements 
between the different assessment tools and certification schemes. Based on a strengthened resolve and with a sense of naive enthusiasm, we began to realize our audacious aim of developing an internationally harmonized language for on-farm sustainability assessment akin to the language that already exists for financial accounting protocols.

The framework will aid farmer understanding and provide a common language for farm-level sustainability. It should take an inclusive approach, allowing all farmers to make incremental steps towards becoming more resilient, sustainable, regenerative, and ultimately a climate change solution.

The framework could also be used by governments to design future public support schemes, by food companies to aid supply chain transparency, by the finance community as a basis for sustainable investment, and by consumers to better understand the relative sustainability of food products that they purchase. In this way, we can reward those producers who are delivering genuine benefit to the environment and public health and subsequently shift the balance of financial advantage towards more sustainable production on a global scale. The Sustainable Food Trust has been consulting with farmers for over four years to help to design the first iteration of a harmonized framework of assessment. The categories of assessment are:

- Soil

- Water

- Air and climate

- Biodiversity

- Energy and resource use

- Nutrient management

- Plant and crop health

- Animal husbandry

- Social capital

- Human capital

- Productivity

\section{Progress to Date}

As we have progressed with this work, the project has increasingly attracted external attention from a wide range of organizations who share an interest in harmonization. These include academic and research institutes, NGOs, certification organizations, food companies and retailers, financial bodies, as well as most recently, policymakers, and government agencies.

At the time of writing this chapter, we are in the midst of conducting a British. Government-funded trial on 30 English farms ranging from arable to mixed cropping and livestock, beef and sheep, pigs, poultry, horticulture, and upland hill farming. The Welsh Government has now also announced that it is its intention to require an annual sustainability audit based on the harmonized framework as a prerequisite for Welsh farmers being able to enter in the new 


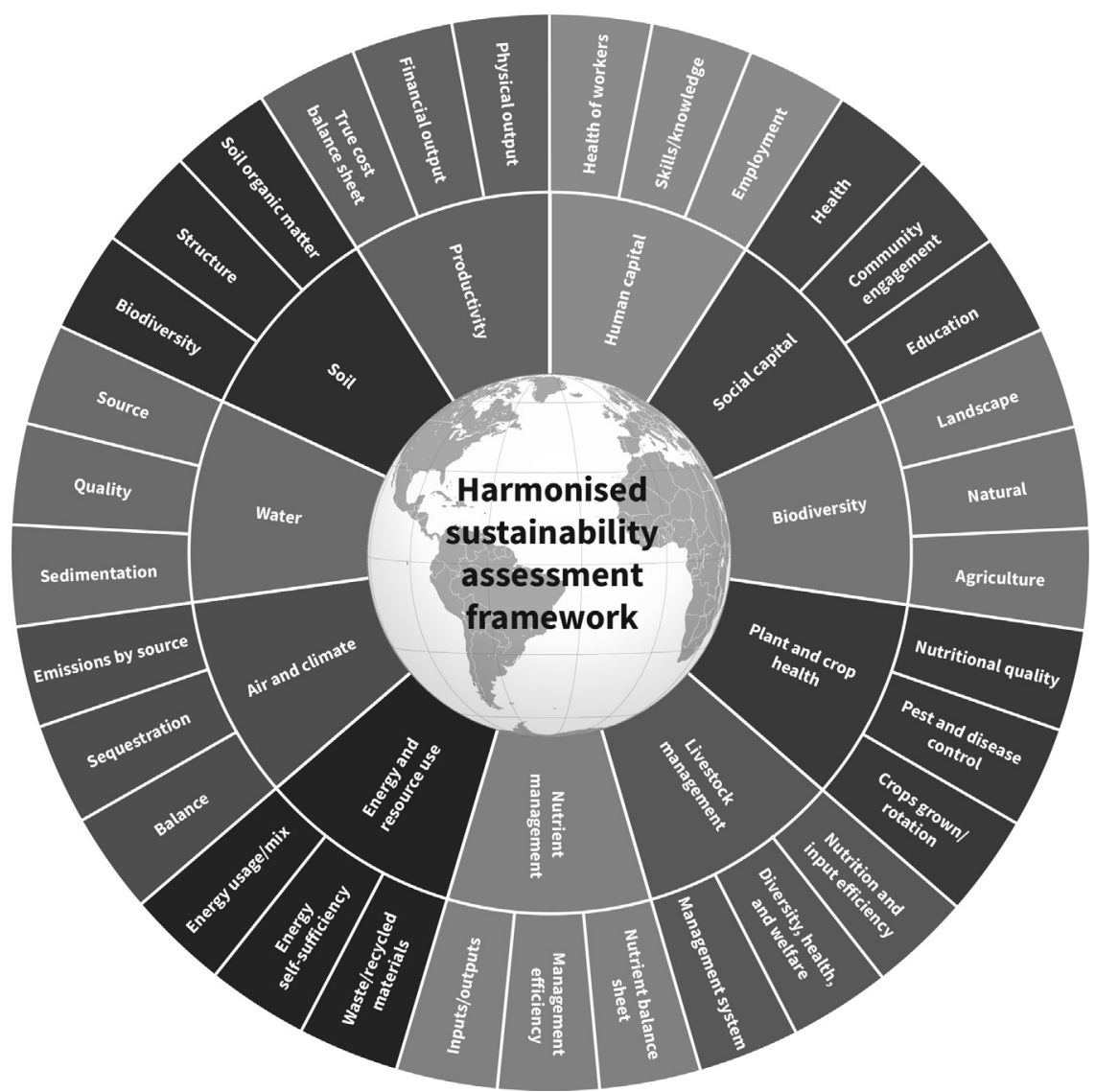

Figure 6.1 Internationally harmonized assessment framework (September 2020). The framework includes 11 categories of assessment with three key indicators under each.

post Brexit farm support scheme. We have also had expressions of interest from several impact investment funds and certification organizations, both in the UK and internationally, who are keen to trial our framework as a means of linking up with others and improving how they measure the change with their farming clients on the ground.

A barrier to harmonized metrics is that many organizations, understandably, work to promote their own, often proprietary frameworks or assessment tools. It is important to state here that at the Sustainable Food Trust, we hold no interest in "owning" the harmonized framework or running a new sustainability assessment scheme. Our ambition is simply to bring all the key players to the table to be able to move towards consensus and then work with organizations actively assessing farms to "superimpose" the framework onto what they are already doing. This way, there can be a great diversity of activities and tools being used for 
multiple purposes, but the presence of a harmonized framework means that data being collected and communicated is consistent and comparable.

Going forward, the most pressing imperative will be to ensure that a harmonized framework for measuring on-farm sustainability couples naturally with the existing high level food system frameworks, including the United Nations' Sustainable Development Goals, Food and Agriculture Organization's (FAO) Tool for Agroecology Performance Evaluation Tool, the Natural Capital Protocol, and the TEEBAgriFood Evaluation Framework, to mention a few. Once such linkages are place, we can then work to identify, categorize, quantify, and eventually monetize the range of externalities, both positive and negative, on all farms across the world in a way that is meaningful to those with their hands in the soil.

\section{Creating an Enabling Policy Environment for Farmers}

The second barrier that we will address is the lack of an enabling policy environment for sustainable food producers. As the harmonization of on-farm assessment process evolves, the focus of attention should then move to governments and government agencies whose interventions will be essential if we are to shift the balance of financial advantage away from the present situation where unsustainable farming pays better than its sustainable counterparts, to a system which rewards the delivery of so called "public goods."

It is a truism that unless we do this, the number of individuals who will be able to practice sustainable agriculture will remain confined to the passionate, the idealistic, the entrepreneurial, and their committed consumer (often wealthy) counterpart, who occupy niche markets and/or are prepared to pay more for more sustainable and healthy food.

\section{"Carrots and Sticks"}

Building on a baseline of common data, it will then be possible to develop policy instruments, such as those that fall under the "polluter pays principle," which ensure that in the future, farming practices which deliver environmental and social "goods" are rewarded in proportion to the benefits delivered (carrots), while those that are causing damage become financially accountable for these impacts (sticks).

An example of such a "stick" under the polluter pays headline would be a tax on nitrogen fertilizer. There is a paradox associated with the use of nitrogen: it has become a seemingly essential component of modern agriculture, brought enormous increases in productivity, and allowed the global population to grow food rapidly. But these benefits come with huge negative impacts including the steady degradation of the natural environment and the soil upon which future food productivity depends. The European Nitrogen Assessment-a major exercise involving over 200 scientists across the European Union-established that the negative impact of the use of nitrogen fertilizer could be valued between $€ 35$ and $€ 230$ billion in 2011 (Sutton and Van Grinsven, 2015). A nitrogen tax would therefore 
constitute a bold initiative to challenge entrenched behavior by making users financial accountable for the negative impact it causes, driving down its use in favor of practices that deliver public benefit.

One such benefit, or "carrot," would be the maintenance or building of soil carbon. If farmers were to be paid to build organic matter (a proxy measure for soil carbon) as a result of their management practices, it could potentially transform the economics for sustainable farming and bring multiple environmental benefits (KeySoil, 2015). Soil organic carbon makes up approximately $50 \%$ of soil organic matter. Degraded soils retain less moisture and are therefore highly vulnerable to droughts. But for every 1\% increase in organic matter in soils, the first foot of soil is able to hold an additional 16,500 gallons of water per acre (40,000 gallons per hectare) (Gould, 2015). Of course to achieve this, we need to reach agreement on which practices have the potential to build soil carbon as well as a common metric and the emergence of a reliable and cost effective means of measuring soil carbon outcomes on farm. If this approach were applied globally, it is estimated that soils (already recognized as the second largest carbon sink after the oceans), would re-sequester significant quantities of the $\mathrm{CO}_{2}$ that have been emitted through the use of fossil fuels over the last $50+$ years.

Until now, governments throughout the world have been reluctant to introduce a polluter pays principle for farming, owing to its possible impact on food prices. This is of course a huge issue that must be addressed, yet the failure to do so amounts to environmental vandalism, pollution, and irresponsible asset stripping of finite natural capital. It is our job now to provide them with the evidence and toolkits to be able to make this an obvious choice for future policy development.

\section{A Thriving Market for Sustainable Food}

The third barrier to change - and potentially the most powerful lever in driving food system transformation - is the market. Even with corrective policy mechanisms in place, in order for sustainable agriculture to become the default model of choice for farmers all over the world, there must be a thriving and transparent market for the output from such systems, which recognizes and rewards the positive benefits being delivered.

It is imperative that the retail sector now makes itself fully aware of the true cost of the food that it sells and must be proactive in demanding food and farming policies that ensure that its supply-chain partners are producing food that is genuinely sustainable from the perspective of the environment, the farmers, and the rural community.

To take the example of food, the most obvious output from farming, the Sustainable Food Trust believes that we need a new innovative, harmonized, and transparent framework for labelling food products, which draws on the results from an annual sustainability assessment (based on the harmonized framework) and empowers consumers by providing accurate information about the degree of sustainability and provenance of the product. This could take the form of a traffic 


\section{Holden \& Jones}

light system or a sliding scale, but importantly the language, categories, and metrics used must be consistent, comparable, and easily understood.

Of course there are now also new and potentially exciting markets for farmers to start tapping into, including those surrounding the delivery of natural capital or carbon offsets. This, together with the recognition that intensive agriculture is a large greenhouse gas emitter, has given rise to the development of a large number of on-farm carbon calculators. Again, unless there is an internationally harmonized framework for measuring farm-level impact under which these schemes and calculators can all fall, there is a huge risk of repeating the "siloized" mistakes made by the certification organizations all those years ago.

\section{Conclusion}

To return to where we started, if we are to restore the global food system "organism" to full health, we need to work from the top down (with governments and the market), from the bottom up (by empowering the millions of farmers who now straddle the majority of the planet's land surface), and in the middle (by empowering citizens to vote for the farming systems that they would like to support through their purchasing powers). It is true that today the patient is sick, but by working within each of these levels, the application of TCA can be used to re-establish farming systems that operate within planetary boundaries and produce food in harmony with nature across the globe.

\section{Box 6.1 A Brief History of True Cost Accounting and Sustainability Assessment From the Farm Up}

1970s: The British Soil Association developed organic standards for the production and marketing of sustainably produced food. The objective behind the scheme, which was eventually adopted all over the world, was to enable farmers who were using sustainable production methods to remain financially viable by attracting a price premium for their products in the market place; this was necessary because of the absence of the polluter pays principle which resulted in "conventional" farming being more profitable than its organic equivalent.

Viewed in market terms, the organic project has been successful; the global retail market for organic food now stands at approximately $€ 100$ billion (Ouest France, 2020), and the EU is currently in the process of setting a target of $25 \%$ of total EU farmland reaching organic production standards by 2030 through its Farm to Fork strategy (European Commission, 2020). Despite these successes, it has now become clear that a partial transition to sustainable farming will not be sufficient to avert runaway climate change and biodiversity loss, with catastrophic impacts on civilization as a whole. In other words, the organic project was treating the symptoms not the cause of the problem-namely the absence of True Cost Accounting. 
1980s/90s: Another early pioneer of the economic discipline of True Cost Accounting (TCA) was Professor Jules Pretty, who published a report in 1991 (Conway and Pretty, 1991) for the first time identifying the extent to which the failure to account for pollution and other negative impacts of intensive farming in monetary terms was disadvantaging farming systems which avoided these costs and delivered true social and environmental benefits.

2010-2016: These factors contributed significantly to the decision to launch the Sustainable Food Trust (SFT), which works internationally to accelerate the transition towards more sustainable food and farming systems. As it became increasingly clear that the absence of True Cost Accounting in food and farming was perpetuating a system that was ultimately destructive of planetary and public health, the work of the SFT became increasingly focused on TCA. The SFT organized a number of events, including: 2011, when the Future of Food conference at Georgetown University, Washington, DC, (at which the Prince of Wales gave a memorable speech in which he mentioned perverse subsidies and the absence of the application of the polluter pays principle); 2012, when the Prince of Wales hosted a meeting at his home, Highgrove, which led to the formation of the Global Alliance for the Future of Food at which True Cost Accounting was voted the most important area for their future work; 2013, when conferences were held in Louisville, Kentucky and London, both on the theme of TCA; and 2016, when a conference was held in San Francisco on The True Cost of American Food.

2014: Pavan Sukdhev decided to focus more of his efforts on food and farming. Hitherto, his work had mainly concentrated on the establishment of the Natural Capital Coalition and the foundation of The Economics of Ecosystems and Biodiversity (TEEB). Subsequently this new interest in food and farming coalesced around the TEEBAgriFood project.

2017: The SFT produced a report, The Hidden Cost of UK Food, whose author, Richard Young, analyzed the known scientific data on food system externalities, highlighting the reality that for every $£ 1$ that is spent in the United Kingdom on food there is another hidden $£ 1$, split 50/50 between negative environmental impacts and damage to public health. In summary, the conclusion of the Hidden Cost report was that the current food pricing system is dishonest and misleading to the general public.

Since 2012: The Global Alliance for the Future of Food has emerged as the most significant advocate of TCA. Members of the Global Alliance partly funded the work of the TEEBAgriFood research program and more recently seed-funded the True Cost Accounting community of practice-a coalition of the key individuals and organizations with an interest in TCA. It has played a key part in strengthening the discipline of TCA and helping those involved to reach out to the wider global community to incorporate TCA principles into future food systems accounting. 


\section{Box 6.2 What Does a Sustainable Farming Operation Look Like?}

The truth is, there is no single "correct" answer to this question, but there are some fundamental principles to which we should all be moving, notably producing as much high-quality, nutritious food as possible, while minimizing the use of non-renewable external inputs, including mineral fertilizers and fossil fuel energy, thereby reducing emissions and environmental pollution, while at least maintaining and preferably building soil fertility and other forms of natural capital. Farming systems should be self-sufficient and as resilient against the external "shocks" as possible, in terms of nutrients, seeds, animal feed, and bedding. They should be agriculturally diverse, including the crop varieties and livestock breeds, and as well as preserving "natural" diversity, in terms of wild plants, insects, birds, and animals. Finally, farming systems must provide a reasonable economic return as well as a high quality of life for the farmer and those who surround the farm.

\section{Box 6.3 Box Acknowledgments}

In describing the progress that we have made with this initiative, it would be inappropriate not to mention the very important work that has been undertaken by other institutions that have been active in accelerating the collective international understanding of True Cost Accounting at the farm level. Specifically, Nadia El-Hage Scialabba at the FAO spent a number of years developing Sustainability Assessment of Food and Agriculture, which was arguably the first and leading initiative in the field of sustainability metrics harmonization and has informed much of our thinking. The International Federation of Organic Agricultural Movements, whose work over a quarter of a century in bringing together organic standards has in many ways contributed towards the emergence of a global awareness of the necessity for measuring food systems sustainability.

A number of individuals have also made important contributions; notably the Prince of Wales raised the issue of the absence of the polluter pays principle as early as the 1980s, and Christy Brown who coined the term "True Cost Accounting" in 2013. The Global Alliance for the Future of Food also deserves tremendous affirmation, as it has prioritized investing in the discipline and the science of TCA right from the outset.

\section{References}

Conway, G.R. \& Pretty, J.N. (1991). Unwelcome Harvest: Agriculture and Pollution. Washington, DC: Earthscan. 
European Commission. (2020). From Farm to Fork. Our food, our health, our planet our future.

Fitzpatrick, I. \& Young, R. (2017). The Hidden Cost of UK Food. Sustainable Food Trust. Available at: http://sustainablefoodtrust.org/wp-content/uploads/2013/04/ HCOF-Report-online-version-1.pdf.

Gould, M.C. (2015). Compost increases the water holding capacity of droughty soils. Michigan State University Extension.

KeySoil. (2015). Profiting from Soil Organic Matter. GY Associates and Rothamsted Research.

Leippert, F., Darmaun, M., Bernoux, M., \& Mpheshea, M. (2020). The potential of agroecology to build climate-resilient livelihoods and food systems. Food and Agriculture Organization and Biovision.

Ouest France. (2020). Dans la baie de Saint-Brieuc, le blé noir conquiert les terres.

Smith, L., Mullender, S., \& Padel, S. (2017). Sustainability Assessment: The Case for Convergence. The Organic Research Centre.

The Economics of Ecosystems and Biodiversity. (2018). TEEB for Agriculture \& Food: Scientific and Economic Foundations. Geneva: United Nations Environment. 